\title{
Bridging the theory-practice dichotomy in nursing: The role of nurse educators
}

\author{
Mohamed Toufic EL Hussein*, Joseph Osuji \\ Faculty of Health and Community Studies, School of Nursing, Mount Royal University, Calgary, Canada
}

Received: June 16, 2016

DOI: $10.5430 /$ jnep.v7n $3 p 20$
Accepted: September 25, 2016 Online Published: October 23, 2016

URL: http://dx.doi.org/10.5430/jnep.v7n3p20

\begin{abstract}
The theory-practice gap is a quandary that many researchers have been trying to resolve for several decades in many practice disciplines. Nursing as a practice discipline encounters this predicament due to the fact that nursing knowledge is not yet well-defined. In this paper, we discuss the meaning of knowledge in general and nursing knowledge in particular. We also discuss the role of nurse educators in delineating the impact of knowledge on nurses' practice and patients' outcomes. Finally we suggest approaches for nursing faculty to bridge the theory-practice gap to assist students to apply theory to their clinical practice.
\end{abstract}

Key Words: Theory-practice gap, Nurse-educator, Nursing knowledge

\section{INTRODUCTION}

The gap between nursing theory and practice is widely documented and debated in the literature. ${ }^{[1-4]}$ Unfortunately, it seems clinicians and educators attempt to deal with this everevolving situation as the new status quo reality of nursing, instead of a problem to be solved. In this paper we argue that while the conundrum of theory-practice gap is growing, it is not receiving the due attention that reflects its significance. In general terms, the theory-practice gap can be defined as the discrepancy between what students acquire through theoretical classroom lectures and what they experience in the clinical setting. Addressed in this paper is a question that continues to challenge nurse educators, how to help undergraduate nursing students translate theoretical learning from the classroom into their clinical practice, and thereby bridge this disparity between nursing theory and practice.

The aim of this opinion/discussion paper is to shed light on the roots of this conundrum and suggest some strategies that may bridge this gap, in addition to advancing the discussion on theory-practice gap and keeping it alive.

\section{BACKGROUND}

To better understand how nurse educators could facilitate the integration of theoretical knowledge into practice, or to minimize the theory-practice gap, it is important to assess the current state of knowledge on this gap. In the later part of the 20th century, there were a number of articles published on the theory-practice gap in the discipline of nursing. Upton ${ }^{[5]}$ suggested that the theory-practice gap in nursing interfered with evidence uptake in clinical practice. Scully ${ }^{[4]}$ described this gap as a void and believed it was an ongoing issue for nursing education to address. Corlett's investigation of this phenomenon from the perspectives of three user groups, students, nurse educators, and clinical preceptors, found that all three groups identified the existence of a dichotomy between nursing theory as taught in the classroom and professional nursing practice as enacted at the bedside. ${ }^{[2]}$ Corlett and

\footnotetext{
${ }^{*}$ Correspondence: Mohamed Toufic EL Hussein; Email: melhussein @mtroyal.ca; Address: Faculty of Health and Community Studies, School of Nursing, Mount Royal University, Calgary, Canada.
} 
colleagues later added that the complex nature of this gap is not yet fully understood. ${ }^{[6]}$ While some participants felt that the gap could be a positive stimuli to student learning, most acknowledged that it needed to be minimized. Rafetty and colleagues ${ }^{[7]}$ noted that engaging in this theory-practice gap debate should be encouraged because the emphasis on the tension between theory and practice in nursing, can only result in keeping clinical practice,, and theory development, up to date, in check, and accountable for the discipline of nursing.

The supposedly evidence of theory-practice gap in nursing in our judgement may not be a unique problem for the discipline of nursing, but speaks to the difficulty in grounding highly abstract intellectual concepts in practice, which exists in many other practice disciplines. The literature also identifies numerous reasons for this. Rolte ${ }^{[8]}$ argued that theory-practice gap exists in nursing because of a misconception about the relationship between nursing theory and professional nursing practice. Other researchers agree with this assertion and have identified specific contributing factors to this that include; students' feelings of powerlessness and abandonment by clinical faculty. ${ }^{[9-11]}$

Although the expectation is that nursing theory should provide the basis for understanding nursing reality in practice, it is acknowledged according to evidence emerging from transition into professional practice literature that undergraduate students experience a disconnection between what they learnt in theory and what is obtainable in practice, as well as during their transition into practice as registered nurses after graduation. New graduates describe their first year experience as professional nurses as not only a tough one, but also one of growth and development. ${ }^{[12]}$ Maben and colleagues ${ }^{[13]}$ added that although new nurses emerged from their programs with a strong set of nursing values, a number of factors effectively sabotaged implementation; including obeying covert rules, lack of support for new graduates, poor nursing role models, time pressures, role constraints, staff shortages, and work overload.

It is evident that there is wide agreement that theory-practice gap exists for undergraduate nursing students, however, there appears to have been limited investigation of suggested strategies to reduce and potentially eliminate this gap. Schuster and colleagues ${ }^{[14]}$ and Grol's ${ }^{[15]}$ study showed that $30 \%-40 \%$ of patients do not receive treatment based on the best available research evidence, while up to $20 \%$ receive treatments that are actually deemed to be harmful to them. As nurse educators, we have encountered numerous situations where students were unable to translate theoretical knowledge into their clinical practice. Developing strategies to enable stu-

Published by Sciedu Press dents to bridge this gap is not only timely, but required for quality professional practice. It is important to continue to bring to awareness and re- focus attention on the gap between theory and practice in the discipline of nursing. In order to advance this debate, the authors considered this conundrum based on evidence from the literature, and offer a conceptual definition of knowledge, and propose common strategies to narrow the theory-practice gap in nursing.

Rodgers ${ }^{[16]}$ contended that nursing practice does not mirror existing nursing knowledge and labeled this problem a "failure" in the integration and application of research findings into practice, this failure he rationalized to be as a result of disengagement between the fundamental principles of holism inherent in the discipline of nursing (person, environment, health, and nursing) and the task oriented and disease focused environment of most nursing practice settings, that create a dissonance between the theoretical background of nurses and the activities they performed in practice. Knowledge is presented to nursing undergraduates in formats with less focus on clinical relevance, as such, the problem is not solely in the development of knowledge but in bridging the "relevance gap" ${ }^{[16]}$ Risjord ${ }^{[17]}$ argued that the theory-practice gap emerges when theory is not "translated into action", adding that this lack of translation is due to the "crush" of workload on nurses, which does not give them enough time or energy to read and reflect. Another challenge that contributes to the gap between theory and practice in nursing is the limited number and experience of newly hired clinical educators. Many new graduate nurses are seeking jobs that conform to the traditional work hours of 8 am to $5 \mathrm{pm}$ and weekends off, thus shortchanging their experiences and the experiences of their students. We are concerned that these nurse lecturers and academics, will not have enough real life experience as nurses to be able to successfully mentor nursing students.

\section{Discussion}

While some scholars have out rightly rejected the need for nursing theories, others have insisted that the real value of nursing can only be represented by a broad theoretical framework that informs and explains what nurses do at the point of client care. Gournay ${ }^{[18]}$ insists that nursing theories are "anachronisms" in the evidence based scheme of modern nursing, while Clarke ${ }^{[19]}$ claims that theories in nursing science did little more than cosmetically enhance the credibility of the profession. Liaschenko ${ }^{[20]}$ considers nursing as a practical rather than a professional knowledge, hence there can neither be theory of nursing nor a gap between purported theory and practice. Larsen and colleagues ${ }^{[21]}$ support this argument and insist there is no gap per se between nursing knowledge and practice, because "theory and practice have 
different logics, they are not a continuum nor are they hierarchically ordered", and "the expression of a gap is a social construct and a product of history and culture in nursing". [21]

On the other hand, an overwhelming majority of nursing scholars agree that a gap exists between nursing knowledge and practice. ${ }^{[1-4]}$ We believe that the differences in perspectives are due to the lack of a clear definition of nursing knowledge. In other words if we know what nursing knowledge is, then theories can be constructed to inform that kind of knowledge, since every profession is legitimized based on its ability to generate and apply unique sets of disciplinary theories/knowledge.

The science of Nursing as a discipline is an identifiable body of knowledge that comprises of paradigms, frameworks and theories. Therefore, the integration of these theories into nursing practice demonstrates an evolutionary pathway for introducing a paradigm shift in nursing and asserts the maturity of the discipline of nursing. There is an increasing recognition among nurse scholars that theory development is crucial to the progress and acceptance of the discipline, hence the growing movement to rejuvenate the discussion and debate on the need for nursing theories, ${ }^{[22,23]}$ and the imperative for these theories to inform and direct nursing practice.

The value of theory development and use within the discipline of nursing cannot be over emphasized. This is because when nurses deliberately use theories to inform their practices, "they can facilitate processes that significantly benefit patients, nurses, the health care system, and the broader environment". ${ }^{[24]}$ When nursing practice becomes deliberate and can be articulated in a common language, the work that nurses do will remain more visible and more valued within the society. Nursing theories will in this way inform practice and also emanate from practice, and such theories emanating from practice will be "viewed as a rich source of new knowledge as practitioners are engaged in creating, as well as modifying knowledge to respond to specific clinical situations". [25]

Nursing knowledge is knowledge that nurses and patients consider "useful and significant" in enhancing their understanding of the processes of human health and illness. ${ }^{[24]} \mathrm{We}$ believe that nursing knowledge refers to the activities that nurses do; and the facts and figures that are organized by nursing concepts and theories. While there are many factors contributing to nursing knowledge, the challenge is to develop a coherent and consistent pathway in the process of knowledge construction. An expected outcome of the development of nursing knowledge is that nurses should expect movement in answering both discipline and clinical prac- tice issues. This is the intent, while the application of the philosophical base to achieve this outcome is the complexity.

It is our understanding that the theory-practice gap in nursing is due to an overreliance on armchair theorizers in generating new knowledge. Notwithstanding the fact that practice is often enacted by practitioners and not researchers, sometimes the knowledge generated by the latter falls short of practical application. Another possible reason could be due to the overdependence on theoretical knowledge created through deductive logic. Although theories can allow its proponents to practice competently when they encounter familiar grounds, however an established theory's deductive limits usually surface when unfamiliar circumstances are encountered.

Mitchell and Cody ${ }^{[26]}$ contended that in order to generate nursing knowledge, this knowledge has to be distinct from other disciplines and should be exclusively derived from nursing theories, and claimed that a "unique knowledge", rather than borrowed knowledge, can guide research and give directions for practice strategies that contribute to the health of individuals in unique ways. Considering the complexity of human beings, we argue that the approach of trying to find a unique body of knowledge is a limitation and a potential barrier to the research process. While it is important to have a theoretical perspective, it is not necessary for it to be discipline-specific. We contend that borrowing knowledge and theories from other disciplines strengthens the discipline of nursing as it helps in viewing phenomenon from a different perspectives. Whether or not nursing knowledge develops from a singular perspective seems to be a moot point, because multiple viewpoints are logically consistent with human reality and therefore calls for a multiplicity of paradigms. Prescriptive approaches limit the development of nursing knowledge due to their singular nature. Moreover, we believe that nursing knowledge development hinges upon the diversity of nursing research. Nurses are expected to attend to the holistic needs of clients; therefore nursing academics and theorists need to develop knowledge from diverse research methods based on different paradigms. Pluralism should not be considered as an undermining commitment to a certain point of view, on the contrary, tolerance for multiple viewpoints should be considered a "virtue"[17] in articulating nursing knowledge.

\section{NURSING THEORY AND CLINICAL PRAC- TICE BRIDGING THE GAP}

Nurses recognize that human sources of information are more practical and valuable than text-based or on-line sources. ${ }^{[27]}$ Pravikoff and colleagues ${ }^{[28]}$ reported similar findings, sug-

ISSN 1925-4040 E-ISSN 1925-4059 
gesting that colleagues are the most popular and widely used source of information to inform practice. Colleagues are readily available and perceived as easier to access and approach. This culture of practice depends heavily on the registered nurse rather than the level of evidence or the significance of the research, thus potentially widening the theory-practice gap. ${ }^{[27]}$ This culture is supported by the lack of an effective vehicle for transferring knowledge from classroom to practice setting, which leads to a tremendous impact on knowledge assimilation. Scholarly articles filled with statistical jargon and philosophical arguments can be a factor in the underutilization of knowledge especially for undergraduate students who often lack the ability to digest this kind of knowledge. Considering the "oral/aural culture in nursing", ${ }^{[29]}$ where nurses prefer to learn from colleagues rather than from text-based or electronic resources, one way of addressing the theory practice gap is to support this position. We argue that a collaborative process between nurse educators and clinical based registered nurses can create a positive environment for research utilization. Nurse educators are expected to support practitioners and student nurses during their practice to ensure safe administration of care and best clinical outcomes. Gibson ${ }^{[30]}$ argued that nurse educators are mandated to maintain standards of care and health care promotion for patients by planning and teaching practitioners current trends and regulations, and added that nurse educators who are creative in a scientific manner are essential for the development of practicing nurses. As nurse educators, our role is as a knowledge conduit that facilitates the sharing, transfer, and implementation of best practice guidelines; we also acknowledge the principles of adult learning and see ourselves as change agents contributing to the professional growth of practicing registered nurses. Part of our responsibility, is also to embrace evidence informed practice and translate relevant knowledge into action. Scholarship is an integral part of this "multidimensional role" ${ }^{[30,31]}$ as nurse educators working with our clinical practice colleagues.

Registered nurses are the end-users of nursing knowledge and often a source of tremendous amount of useful information. Horizontal and open lines of communication between practitioner and nurse educator is needed to tackle emerging clinical issues. The nurse educator should not only ensure that theoretical knowledge is properly integrated for the practitioner to understand, but should also demonstrate how such knowledge can be consolidated and most importantly applied. The nurse educator acts as a link liaising practitioners to the most up to date evidence and should be perceived as support rather than an evaluator.

Promotion of research within practice contexts is another strategy the nurse educator can use to enhance the integration

Published by Sciedu Press of knowledge into practice. Getting practitioners involved in the research process from implementation to evaluation can draw their attention to the significance of knowledge development in their practice, and potential impact of nursing theory on nursing practice. We believe that the conundrum of theory-practice gap in nursing can only be partially rectified as new knowledge is being developed and applied on an ongoing basis. Developing reflective skills can help practitioners recognize the coherence between theoretical knowledge and practical skills. Reflection, critical thinking, and reflective practice are effective tools to bridging the theory-practice gap. ${ }^{[32]}$ Changing attitudes towards research enhances the research utilization behavior in nursing practice thus narrowing the theory practice gap.

\section{Conclusion}

Nurses prefer to use the knowledge they gain from colleagues during practice, this preference is a double-edged sword as the information gained could be flawed or misinterpreted. The nurse educator can ensure that this knowledge is up to date, consistent, and valid for utilization at nursing practice settings. The nurse educator can share experiential knowledge that is characterized by a high degree of conviction in its potential to impact the practice of nurses and the patients' outcomes. Nurses usually have faith in the validity and authority of the knowledge obtained from the nurse educator, as the latter is usually a member of the health care team. The growth of nursing knowledge proceeds from clinical practice as such nurse educators should work closely with researchers to generate evidence based solutions for these problems.

Nurse educators must be pivotal in this process of reducing the theory-practice gap, creating relevance for students, helping them apply theoretical knowledge to practice situations, and bridging the ideal with the real. Nursing theories provide a general focus for curriculum design and decision making and therefore constructing teaching and learning activities in nursing and applying a theory of nursing in nursing education becomes imperative in assisting Students bridge the gap between theory and practice.

Although there may be a lack of empirical evidence to prove that these factors do facilitate reduction of the theory-practice gap, conclusive evidence is needed before a strategy aiming to better integrate theory into practice of nursing can be developed.

As nurse educators, there is much that we can do to build and strengthen the bridges between theoretical and practical learning. Nurse educators need to assist students to see that theory underscores practice. From the literature, it has been 
identified that a theory-practice gap exists and that there are some but not enough strategies in place in academic environments to adequately address this.

\section{CONFLiCTS OF InTEREST DisClOSURE}

The authors declare that there is no conflict of interest.

\section{REFERENCES}

[1] Ahmad S, Mohannad E, Rami M. Theory practice gap in nursing education: a qualitative perspective. Journal of Social Sciences. 2015; 11(1): 20-26. http://dx.doi.org/10.3844/jssp. 2015 .20 .29

[2] Corlett J. The perceptions of nurse teachers, student nurses and preceptors of the theory-practice gap in nurse education. Nurse Education Today. 2000; 20(6): 499-505. PMid:10959139 http: //dx.doi.org/10.1054/nedt.1999.0414

[3] Hatlevik IKR. The theory-practice relationship: reflective skills and theoretical knowledge as key factors in bridging the gap between theory and practice in initial nursing education. Journal of Advanced Nursing. 2011; 68(4): 868-877. PMid:21790737 http: //dx.doi.org/10.1111/j.1365-2648.2011.05789.x

[4] Scully NJ. The theory-practice gap and skill acquisition: An issue for nursing education. Collegian. 2011; 18(2): 93-98. http: //dx.doi.org/10.1016/j.colegn.2010.04.002

[5] Upton DJ. How can we achieve evidence-based practice if we have a theory-practice gap in nursing today? Journal of Advanced Nursing. 1999; 29(3): 549-555. http://dx.doi.org/10.1046/j.1365-2 $648.1999 .00922 . \mathrm{x}$

[6] Corlett J, Twycross A. Negotiation of care by children's nurses: lessons from research. Paediatric Nursing. 2006; 18(8): 34-37. PMid:17042309 http://dx.doi.org/10.7748/paed.18.8.34. s26

[7] Rafferty AM, Allcock N, Lathlean J. The theory/practice 'gap': taking issue with the issue. Journal of Advanced Nursing. 1996; 23(4): 685-691. http://dx.doi.org/10.1111/j.1365-2648. 1996. tb00038.x

[8] Rolte NA. Hospital nursing. Nursing. 2001; 31(4): 32hn8. http: //dx.doi.org/10.1097/00152193-200131040-00013

[9] Dadgaran I, Parvizy S, Peyrovi H. A Global Issue in Nursing Students' Clinical Learning: The Theory-Practice Gap. Procedia - Social and Behavioral Sciences. 2012; 47: 1713-1718. http: //dx.doi.org/10.1016/j.sbspro.2012.06.888

[10] Ousey K, Gallagher P. The theory-practice relationship in nursing: A debate. Nurse Education in Practice. 2007; 7(4): 199205. PMid:17689445 http://dx. doi.org/10.1016/j. nepr. 20 07.02 .001

[11] Jonsen E, Melender H, Hilli Y. Finnish and Swedish nursing students experiences of their first clinical practice placement-a qualitative study. Nursing Education Today. 2013; 33: 297-302. PMid:22795745 http://dx.doi.org/10.1016/j.nedt. 2012.06.012

[12] Wangensteen S, Johansson I, Nordström G. The first year as a graduate nurse - an experience of growth and development. Journal of Clinical Nursing. 2008; 17(14): 1877-1885. PMid:18578762 http://dx.doi.org/10.1111/j.1365-2702.2007.02229.x

[13] Maben J, Latter S, Clark JM. The theory-practice gap: impact of professional-bureaucratic work conflict on newly-qualified nurses. Journal of Advanced Nursing. 2006; 55(4): 465-477. PMid:16866842 http://dx.doi.org/10.1111/j.1365-2648.2006.03939.x

[14] Schuster MA, McGlynn EA, Brook RH. How good is the quality of health Care in the United States? The Milbank Quarterly. 1998; 76:
517-563. PMid:9879302 http://dx.doi.org/10.1111/1468-0 009.00105

[15] Grol R. Successes and failures in the implementation of evidence based guidelines for clinical practice. Medical Care. 2001; 39: 46-54 http://dx.doi.org/10.1097/00005650-200108002-00003

[16] Rodgers BL. Developing nursing knowledge: Philosophical traditions and influences. Philadelphia, PA: Lippincott, William, \& Wilkins; 2005.

[17] Risjord M. Nursing knowledge: Science, practice and philosophy. Oxford, United Kingdom: Wiley-Blackwell; 2010.

[18] Gournay K. Mental health nursing in 2001-what happens next? Journal of Psychiatric and Mental Health Nursing. 2001; 8: 1-3 http://dx.doi.org/10.1046/j.1351-0126.2001.00460.x

[19] Clarke L. Declaring conceptual independence from obsolete professional affiliations. In Key Debates in psychiatric/mental health nursing (Cutliffe, J. R. \& Ward, M. F., eds), Churchill Livingstone Elsevier, Edinburgh. 2006; 70-83.

[20] Liaschenko J. Book Review: Ethics and evidence-based medicine: fallibility and responsibility in clinical science. Nursing Ethics. 2003; 10(5): 569-569. http://dx.doi.org/10.1177/0969733003010 00518

[21] Larsen K, Adamsen L, Bjerregaard L, et al. There is no gap per se between theory and practice: Research knowledge and clinical knowledge are developed in different contexts and follow their own logic. Nursing Outlook. 2002; 50(5): 204-212. http://dx.doi.o $\mathrm{rg} / 10.1067 / \mathrm{mno} .2002 .127724$

[22] McCrea N. Whither nursing models? The value of nursing theory in the context of evidence-based practice and multidisciplinary health care. Journal of Advanced Nursing. 2012; 68(1): 222229. PMid:21906131 http://dx.doi.org/10.1111/j.1365-2 648.2011.05821.x

[23] Pridmore JA, Murphy F, Williams A. Nursing models and contemporary nursing 2: can they raise standards of care? Nursing Times. 2010; 106: 22-25. PMid:20642215

[24] Reed PG, Lawrence LA. A paradigm for the production of practicebased knowledge. Journal of Nursing Management. 2008; 16: 422432. PMid: 18405259 http://dx.doi.org/10.1111/j.1365-2 $834.2008 .00862 . x$

[25] Kim HS. Critical reflective inquiry for knowledge development in nursing practice. Journal of Advanced Nursing. 1999; 29(5): 12051212.

[26] Mitchell GJ, Cody WK. The role of theory in qualitative research. Nursing Science Quarterly. 1993; 6(4): 170-178. PMid:8265050 http://dx.doi.org/10.1177/089431849300600405

[27] Thompson C, McCaughan D, Cullum N, et al. The accessibility of research-based knowledge for nurses in United Kingdom acute care settings. Journal of Advanced Nursing. 2001; 36: 11-22. http://dx.doi.org/10.1046/j.1365-2648.2001.01938.x

[28] Pravikoff DS, Tammer AB, Pierce ST. Readiness of U.S. Nurses for Evidence- Based Practice: many don't understand or value research and have had little or no training to help them find evidence on which to base their practice. American Journal of Nursing. 2005; 105: 40-51. http://dx.doi.org/10.1097/00000446-200509000-00025 
[29] Considine J, Khaw D. Clinical nurse research consultant: A clinical and academic role to advance practice and the discipline of nursing. Journal of Advanced Nursing. 2011; 67: 2275-2283. PMid:21592190 http://dx.doi.org/10.1111/j.1365-2648.2011.05687.x

[30] Gibson CG. Nurse educator roles and long-term care. Journal for Nurses in Staff Development. 2011; 27: 259-261. PMid:22108062
http://dx.doi.org/10.1097/NND . Ob013e3182371136

[31] Klab KA. Core competencies of nurse educators: Inspiring excellence in nurse educator practice. Nursing Education Perspectives. 2008; 29: 217.

[32] Benner P, Tanner CA, Chesla CA. Expertise in nursing practice: Caring, Clinical Judgment and Ethics. New York. Springer; 2009. 